\title{
FUNGOS ENDOFÍTICOS EM FOLHAS DE ERVA-MATE (Ilex paraguariensis A. St.-Hil.)
}

\author{
Ida Chapaval Pimentel*, Fábio Rosalinski Kuczkowski**, Maria Aparecida Chime**, \\ Celso Garcia Auer***, Albino Grigoletti Junior*** \\ *Eng ${ }^{\mathrm{a}}$. Agrônoma, Dr ${ }^{\mathrm{a}}$,, Depto. Patologia Básica, UFPR - ida@ufpr.br \\ ** Graduando em Biologia, UFPR \\ ***Eng. Florestal, Dr., Embrapa Florestas - auer@cnpf.embrapa.br; albino@cnpf.embrapa.br \\ Recebido para publicação: 09/08/2005 - Aceito para publicação: 10/02/2006
}

\begin{abstract}
Resumo
Este estudo teve como objetivo analisar o efeito da idade de folhas de erva-mate, colhidas em ervas cultivadas e nativas, sobre a população de fungos endofíticos. Como resultado, verificou-se que ocorre uma maior diversidade de fungos endofiticos em folhas adultas de erva-mate do que em folhas jovens. A diversidade foi maior nas plantas nativas, com uma microbiota mais abundante, decorrente de um ambiente sombreado e úmido, mais propício para o seu desenvolvimento, diferente de um agroecossistema. Plantas de erva-mate nativa apresentaram fungos endofíticos de gêneros com potencial de biocontrole que deveriam ser testados quanto à capacidade de induzir proteção contra pragas e doenças.
\end{abstract}

Palavras-chave: Filoplano; Ilex paraguariensis; micologia.

\begin{abstract}
Endophytic fungi on mate (Ilex paraguariensis A. St.-Hil.) leaves. This study was done to analyze effects of leaves age of mate collected in cultivated and native plants, on the endophytic fungal population. Diversity of endophytic fungi in old leaves was higher than in young leaves. Diversity was also higher in native plants, with an abundant microbiota, probably in consequence of a shadowed and humid environment, very different than in agroecosystems. Plants of native mate showed genera of fungi with potential for biocontrol that should be tested on its ability to induce protection against insects and diseases.
\end{abstract}

Keywords: Ilex paraguariensis; mycology; phylloplane.

\section{INTRODUÇ̃̃O}

A erva-mate (Ilex paraguariensis A. St.-Hil.) é uma planta pertencente à família Aquifoliaceae. Essa família é considerada cosmopolita, ocorrendo em quase todas as regiões do planeta, totalizando um total de 600 espécies (GILBERT, 1995). A erva-mate é a principal espécie comercial plantada e explorada no Cone Sul, em países como Argentina, Brasil e Paraguai. A planta I. paraguariensis é uma espécie umbrófila, de clima temperado subtropical, com chuvas regularmente distribuídas ao longo do ano (CARVALHO, 1994). Ocorre naturalmente em solos profundos, bem drenados, ligeiramente ácidos, mas não tolera solos alagados e muito compactados.

A importância da erva-mate, atualmente, concentra-se na área de bebidas por infusão, como chás, chimarrão, tererê e sucos (CARVALHO, 1994). O consumo do chá descende de um costume indígena, que o utilizava como estimulante. Muitos estudos têm sido feitos a respeito da utilização de produtos e subprodutos da erva-mate em outras aplicações. Dentre as já existentes, temos a utilização como conservante natural, corante natural, estimulante do sistema nervoso e no tratamento de hipertensão, bronquite e pneumonia, bactericida, como esterilizante natural e na fabricação de cosméticos (BASSANI; CAMPOS, 1997).

Como o ambiente típico da erva-mate é a Mata Atlântica, floresta com grande biodiversidade, isso pode explicar as diferenças morfológicas visíveis nas plantas. Aspectos como altura da planta, tamanho e formato das folhas, suscetibilidade às doenças e pragas variam de planta para planta, 
dependendo do ambiente em que vivem. Tais variações também são condicionadas pelos fatores climáticos, como intensidade e duração da radiação solar, e pelas variações genéticas preestabelecidas (COELHO et al., 2002), ou até mesmo pela presença ou ausência de microrganismos endofíticos (MELO; AZEVEDO, 1998).

A presença de microrganismos endofíticos pode ser de grande importância ecológica para a ervamate quanto ao controle natural de microrganismos fitopatogênicos. Pode-se considerar endofítico um microrganismo que habitar, ao menos durante uma fase de seu ciclo de desenvolvimento, o interior de um vegetal sem lhe causar doença ou danos. Os fungos endofíticos vivem geralmente nas partes aéreas das plantas, como folhas e caules (BORGES, 1999). Os fungos endofíticos podem aumentar a resistência do hospedeiro à ação dos predadores e de algumas doenças. Pesquisas comprovam a ação antifúngica, ou seja, que evitam a colonização do hospedeiro por fungos fitopatogênicos (TAECHOWISAN et al., 2003), assim como a ação antagônica contra bactérias fitopatogênicas (LU et al., 2000), evitando a formação de cancros (SMITH et al., 1996). Existem casos descritos de proteção indireta, induzida por fungos endofíticos, em que metabólitos produzidos por estes aumentaram a resistência de nematóides entomopatogênicos, que por sua vez deixaram o hospedeiro mais resistente às pragas (KUNKEL et al., 2004).

A micologia da erva-mate tem sido restringida aos estudos das populações fúngicas associadas a essa planta na forma de patologias e descrições micológicas (AUER; GRIGOLETTI JUNIOR, 1995) e na análise microbiológica de alimentos (BORGES et al., 2000; MARUCCI et al., 2000; SAATKAMP et al., 2000). Sobre os endofíticos em erva-mate, Penna (2000) estudou a presença desses microrganismos em pecíolos, folhas e sementes, verificando interações entre a quantidade de fungos e o órgão da planta e a procedência das matrizes. Esse autor, contudo, não avaliou o efeito do estádio da folha, bem como o tipo de cultivo da erva-mate, sobre a população de fungos endofíticos.

Este trabalho teve por objetivos isolar e identificar fungos endofíticos de folhas de $I$. paraguariensis e comparar, de modo quantitativo, as populações dos fungos endofíticos obtidos de plantas nativas e cultivadas, em folhas jovens e adultas.

\section{MATERIAL E MÉTODOS}

A coleta das amostras de erva-mate foi realizada em agosto de 2004, na área experimental da Embrapa Florestas, localizada em Colombo (PR), e os estudos microbiológicos foram realizados no Laboratório de Microbiologia do Departamento de Patologia Básica da Universidade Federal do Paraná.

Foram coletadas aproximadamente 100 folhas de plantas cultivadas e 100 folhas de plantas nativas, colhidas de forma aleatória, em diferentes plantas (nativas e cultivadas). A coleta foi realizada em porções mais apicais (folhas jovens) e em porções mais basais (folhas adultas). Trabalhou-se com quatro grupos de folhas: folhas cultivadas (jovens e adultas) e folhas nativas (jovens e adultas).

As amostras foram lavadas em água corrente, sem ferir as amostras e descartando-se as danificadas. Antes do processo de desinfestação externa das folhas, estas tiveram seus pecíolos vedados com parafina, a fim de evitar que os agentes de desinfecção penetrassem por essa abertura, alterando o resultado real do isolamento. A desinfecção superficial deu-se através de lavagens por imersão. Primeiramente, duas vezes em água destilada esterilizada por 30 segundos, seguida de solução de álcool etílico a $70 \%$ por 1 minuto, de solução de hipoclorito de sódio a $3 \%$ por 4 minutos, novamente em solução de álcool etílico a $70 \%$ por 30 segundos e três vezes em água destilada esterilizada por 1 minuto, para retirar os resquícios dos agentes esterilizantes, conforme utilizado por Pimentel (2001).

As folhas foram cortadas em fragmentos circulares de aproximadamente $6 \mathrm{~mm}$. Seis fragmentos foram transferidos para placas de Petri contendo meio de cultivo BDA (infuso de $200 \mathrm{~g}$ de batata; dextrose, $20 \mathrm{~g}$; ágar, $15 \mathrm{~g}$; tetraciclina, $100 \mathrm{mg} / \mathrm{L}$; água destilada q.s.p., $1000 \mathrm{ml}$ ) e incubados à temperatura ambiente $\left(28 \pm 2{ }^{\circ} \mathrm{C}\right)$, durante 30 dias. Para se conhecer o grau de contaminação de fungos e bactérias, retirou-se $0,1 \mathrm{ml}$ da última água da seqüência de lavagem e colocou-se em duas placas contendo BDA, uma incubada a $28{ }^{\circ} \mathrm{C}$ e outra a $37^{\circ} \mathrm{C}$. Foram semeadas 400 placas no total, sendo 100 para cada um dos tratamentos.

O crescimento das colônias fúngicas foi acompanhado diariamente. À medida que surgiam, eram transferidas para tubos de ensaio contendo BDA inclinado, à temperatura ambiente, e depois armazenadas a $4{ }^{\circ} \mathrm{C}$. 
As colônias de aspecto similar foram agrupadas, com a finalidade de facilitar o estudo. Em seguida, os grupos foram repicados para tubos de ensaio contendo meio BDA, para garantir a presença de apenas um exemplar na amostra a ser posteriormente identificada. Para isso, colocaram-se fragmentos de micélio de cada um dos isolados dos fungos em tubos de ensaio contendo uma solução de Tween 80 a 0,1 $\%$, que foi agitado em vórtex, em velocidade máxima, até que estruturas visíveis fossem dissolvidas. Depois, alíquotas de $20 \mathrm{ml}$ foram semeadas em placas de Petri contendo meio BDA mais tetraciclina, com auxílio da alça de Drigalski. Em seguida, as placas foram incubadas à temperatura ambiente, verificando-se os tipos de colônias desenvolvidas.

Realizou-se a observação das estruturas de reprodução pelo método de cultura em lâmina, ou técnica do microcultivo (KERN; BLEVINS, 1999), e sua identificação baseou-se em literatura especializada (BOOTH, 1971; LARONE, 1993; MENEZES; OLIVEIRA, 1993; Barnett e Hunter, 1972).

Os dados obtidos a partir do isolamento dos fungos endofíticos foram submetidos à análise estatística pelo teste do qui-quadrado (GOMES, 1978) para verificar se a diferença observada entre a quantidades de fungos endofíticos em plantas cultivadas e nativas (folhas jovens e velhas) foi significativa.

\section{RESULTADOS E DISCUSSÃO}

Foram isolados um total de 4.406 colônias dos fragmentos de folhas, com um maior número de colônias em folhas adultas e em erval nativo (Tabela 1), e houve diferenças significativas entre os fatores origem e idade. Essa variação pode ser devida à exposição da folha à luminosidade, pois a planta nativa encontra-se dentro da mata, protegida da radiação solar, o mesmo não ocorrendo com as plantas cultivadas, que estão sujeitas a uma maior exposição. Essa diferença de intensidade e período de exposição pode repercutir diretamente na população de fungos endofíticos, organismos sensíveis à radiação solar (PETRINI, 1986). Um outro fator que pode afetar diretamente os fungos endofíticos é a umidade do ambiente. Sob a mata, existe um ambiente mais úmido, mais propício à sua sobrevivência, enquanto que, a pleno sol, a umidade tende a ser menor, ocorrendo o ressecamento da folha.

Grande parte dos fungos apresenta baixa tolerância ou mostra-se pouco tolerante à radiação, o que poderia explicar a menor diversidade encontrada nas plantas cultivadas. Além disso, o ambiente em que vivem as plantas nativas está muito mais favorável à colonização, pois é um ambiente mais sombreado e úmido, o que pode aumentar o número e, conseqüentemente, a diversidade de fungos. Acredita-se, também, que os agentes vetores de fungos endofíticos (MELO; AZEVEDO, 1998) sejam mais atuantes na mata, sob uma condição ecológica protegida de predadores.

Tabela 1. Número total de colônias de fungos endofíticos obtidas de folhas de erva-mate, segundo a origem da planta e idade da folha.

Table 1. Total number of colonies of endofitic fungi obtained from mate leaves related to origin and leaf age.

\begin{tabular}{|c|c|c|c|}
\hline \multirow{2}{*}{ Estádio da folha } & \multicolumn{2}{|c|}{ Origem da erva-mate } & \multirow{2}{*}{ Total } \\
\hline & Cultivado & Nativo & \\
\hline Adulta & $1.166 \mathrm{ax}^{*}$ & $1.280 \mathrm{ax}$ & $2.446 \mathrm{~A}$ \\
\hline Jovem & 887 by & $1.073 \mathrm{bx}$ & $1.960 \mathrm{~B}$ \\
\hline Total & $2.053 \mathrm{X}$ & $2.353 \mathrm{Y}$ & 4.406 \\
\hline
\end{tabular}

Dez grupos de fungos foram identificados (Tabela 2), e um agrupou aqueles não identificados, totalizando 133 grupos de morfotipos de fungos endofíticos. Para a erva-mate nativa, foram identificados 34 grupos em folhas jovens e 43 nas folhas adultas. Em erva-mate cultivada, 25 grupos foram identificados em folhas jovens e 31 em folhas adultas. O tratamento que apresentou uma maior diversidade de fungos endofíticos foi o das plantas nativas e folhas adultas, número que diminuiu nas plantas nativas de folhas jovens. Nas plantas cultivadas, o número de fungos endofíticos foi ainda menor no geral, sendo menor ainda nas folhas jovens. 
Tabela 2. Número de colônias de gêneros de fungos endofíticos isolados de folhas de erva-mate, de acordo com a origem da planta e idade da folha.

Table 2. Number of colonies of endofitic fungi genera isolated from mate leaves related to origin and leaf age.

\begin{tabular}{lccccc}
\hline Fungo & \multicolumn{2}{c}{ Erva cultivada } & \multicolumn{2}{c}{ Erva nativa } & \multicolumn{2}{c}{ Total } \\
\cline { 2 - 5 } & Folha jovem & Folha velha & Folha jovem & Folha velha & \\
\hline Acremonium sp. & $-*$ & - & 4 & 12 & 16 \\
Aspergillus sp. & 19 & 4 & 4 & 3 & 30 \\
Colletotrichum sp. & - & 6 & 2 & 1 & 9 \\
Dendrophoma sp. & - & - & - & - & - \\
Fusarium sp. & 3 & 3 & 13 & 15 & 14 \\
Penicilium sp. & 2 & 11 & 3 & - & 41 \\
Rhizoctonia sp. & - & - & - & - & 3 \\
Scopulariopsis sp. & - & - & - & 1 & 2 \\
Trichoderma sp. & 1 & 3 & 6 & 3 & - \\
Verticillium sp. & - & - & 34 & 43 & 13 \\
Fungos não identificados & - & 4 & 31 & - & 133 \\
\hline Total & 25 & &
\end{tabular}

*ausência de colônias; - ausence of colonies.

Penna (2000) encontrou onze grupos de fungos (936 isolados) pertencentes aos gêneros Phyllosticta, Colletotrichum, Ascochyta, Xylaria, Nodulisporum, Cladosporium e Fusarium, outros não identificados das famílias Dematiaceae e Moniliaceae e também Mycelia sterilia. Nesse estudo, as plantas estavam em um plantio a pleno sol (cultivado) e não houve segmentação da pesquisa quanto ao estádio da folha (jovem ou adulta). Outro aspecto ressaltado pela pesquisa de Penna (2000) foi a necessidade de se escolher um meio de cultura adequado e a temperatura de incubação para o isolamento de fungos endofíticos. Houve uma maior quantidade de isolados em placas contendo meio BDA suplementado com tetraciclina, incubadas a $28{ }^{\circ} \mathrm{C}$ (no presente estudo, utilizou-se do mesmo meio, porém incubado a $25^{\circ} \mathrm{C}$ ).

A maior diversidade de fungos endofíticos nas folhas adultas, em ambos os tratamentos, está provavelmente relacionada com o maior tempo de colonização do endófito do que o das folhas jovens (PEREIRA et al., 1993; PETRINI, 1991; RODRIGUES; SAMUELS, 1994).

Dentre os gêneros observados, destacam-se fungos patogênicos dos gêneros Colletotrichum (agente da antracnose), Fusarium (agente da podridão de estacas), Rhizoctonia (agente do tombamento de mudas) (AUER; GRIGOLETTI JUNIOR, 1995). Outros fungos interessantes são pertencentes aos gêneros Trichoderma e Verticillium, agentes de controle biológico de doenças de plantas e de insetos, respectivamente (VIÉGAS, 1979). Os fungos Aspergillus sp. e Penicillium sp. já foram encontrados em grande quantidade como contaminantes de erva-mate processada para comercialização, como erva para chimarrão, e encontrados como endófitos em maior freqüência.

Especificamente a Colletotrichum sp., Hörner et al. (2000), estudando a contaminação de explantes de erva-mate in vitro, relacionou duas espécies após desinfecção com álcool $70 \%$ e solução de hipoclorito de sódio. Provavelmente, os fungos Colletotrichum spp., considerados como contaminantes, na verdade eram endófitos que, após o tratamento de limpeza dos explantes, puderam se desenvolver no meio de cultivo.

Os fungos endofíticos podem agir de maneira antagônica, neutra ou até benéfica para o vegetal hospedeiro, exibindo vários graus de interdependência fisiológica e ecológica. Muitas vezes, os metabólitos produzidos por fungos endofíticos podem ser neutros ou terem ação antagônica para o hospedeiro. Em outros casos, são de grande importância para a farmacologia. Existem pesquisas que comprovam a ação antioxidante, de grande importância para a indústria de cosméticos (STROBEL et al., 2002), e antitumorais, que podem parar o desenvolvimento ou até impedir a formação de tumores (STROBEL et al., 1997), de alguns fungos somente quando endofíticos.

$\mathrm{O}$ fato de plantas nativas apresentarem Trichoderma e Verticillium poderia explicar a menor quantidade ou a ausência de pragas e doenças, em relação às plantas cultivadas. Ervais nativos, que estão sob um ambiente de equilíbrio, apresentam menor incidência de insetos, em decorrência da presença de inimigos naturais (PENTEADO, 1995). Assim, a condução de ervais nativos, sob a mata, seria recomendada para a produção orgânica de erva-mate, para eliminar naturalmente os problemas fitossanitários. 
De acordo com os resultados, os fungos endofíticos em erva-mate foram verificados em quantidades significativamente superiores em folhas adultas presentes em erval nativo. Recomenda-se, assim, que em futuros estudos para obtenção de fungos endofíticos em erva-mate sejam feitas coletas de folhas adultas de I. paraguariensis sob condições de sombreamento em florestas umbrófilas.

\section{CONCLUSÕES E RECOMENDAÇÕES}

Como conclusão, verificou-se que ocorre uma maior quantidade de fungos endofíticos em folhas adultas de erva-mate do que em folhas jovens, e da mesma forma uma maior quantidade em plantas da mata do que em plantas presentes a céu aberto.

As informações deste trabalho revelaram que existem vários fungos endofiticamente associados com as folhas de erva-mate. A presença de certos grupos que são considerados antagônicos a patógenos e entomopatogênicos permite considerar a hipótese de que atuem no controle biológico de pragas, sob condições naturais de mata. Desse modo, o aprofundamento do estudo desses fungos pode abrir caminho para sua utilização no controle biológico das pragas da erva-mate.

\section{REFERÊNCIAS}

AUER, C. G.; GRIGOLETTI JUNIOR, A. Doenças da erva-mate. Summa Phytopathologica, Jaguariúna, v. 21, n. 3-4, p. 195-198, 1995.

BASSANI, V. L.; CAMPOS, A. M. Desenvolvimento de extratos secos nebulizados de Ilex paraguariensis St. Hil., Aquifoliaceae (erva mate) visando a exploração do potencial do vegetal como fonte de produtos. In: CONGRESSO SUL-AMERICANO DA ERVA MATE, 1., REUNIÃO TÉCNICA DA ERVA MATE, 2., 1997, Curitiba, Anais... Colombo: EMBRAPA/CNPF, 1997, p.69-87. (EMBRAPA/CNPF, Documentos, 33).

BARNETT, H. L.; HUNTER, B. B. Illustrated genera of imperfect fungi. 3.ed. New York: MacMillan, 1972. 241p.

BOOTH, C. The genus Fusarium. Kew: Commonwealth Mycological Institute, 1971. 237p.

BORGES, L. R. Isolamento de fungos potencialmente micotoxigênicos em erva-mate (Ilex paraguariensis St. Hill.). 1999. 10f. Trabalho de Conclusão de Curso. (Graduação em licenciatura em Ciências Biológicas) - Universidade Federal do Paraná, Curitiba.

BORGES, L. R.; PIMENTEL, I. C.; BEUX, M. R.; TALAMINI, A. Isolamento de fungos potencialmente micotoxicogênicos em erva-mate (Ilex paraguariensis St. Hil.). In: CONGRESSO SUL-AMERICANO DA ERVA MATE, 2., REUNiÃO TÉCNICA DA ERVA MATE, 3., 2000, Porto Alegre, Anais.... Porto Alegre: UFRGS/FEPAGRO, 2000, p.155-157.

CARVALHO, P. E. R. Ilex paraguariensis Saint-Hilaire; erva-mate. In: Espécies florestais brasileiras: recomendações silviculturais, potencialidades e uso da madeira. Colombo: EMBRAPA-CNPF; Brasília: EMBRAPA-SPI, 1994. p. 280-287.

COELHO, G. C.; MARIATH, J. E. de A.; SCHENKEL, E. P. Populational diversity on leaf morphology of Maté (Ilex paraguariensis, A. St.-Hil., Aquifoliaceae), Brazilian Archives of Biology and Technology, Curitiba, v. 45, n. 1, p. 47-51, 2002.

GILBERT, G. C. Ilex en sudamerica: florística sistemática y potencialidades com relación a un banco de germoplasma para la yerba mate. In: WINGE, H.; FERREIRA, A.G.; MARIATH, J.E.A. Erva-mate; biologia e cultura no Cone Sul. Porto Alegre: UFRGS, 1995. p.303-312.

GOMES, F. P. Iniciação à estatística. 6.ed. São Paulo: Nobel, 1978. 211p.

HÖRNER, L. de A.; AUGUSTIN, L.; FORCELINI, C. A.; MIELKE, M. S.; SUZIN, M.; DENARDIN, N. D. Estudo do desenvolvimento e identificação dos agentes contaminantes da erva-mate cultivada in vitro. In: CONGRESSO SUL-AMERICANO DA ERVA MATE, 2., REUNIÃO TÉCNICA DA ERVA MATE, 3., 2000, Porto Alegre, Anais... Porto Alegre: UFRGS/FEPAGRO, 2000.

KERN, M. E.; BLEVINS, K. S. Micologia médica. 2.ed. São Paulo: Premier, 1999. 256p. 
KUNKEL, B. A.; GREWAL, P. S.; QUIGLEY, M. F. A mechanism of acquired resistance against na entomopathogenic nematode by Agrotis ipsilon feeding on perennial ryegrass harboring a fungal endophyte, Biological Control, San Diego, v. 29, n. 1, p. 100-108, 2004.

LARONE, D. H. Medically important fungi; a guide to identification. Washington: American Society for Microbiology, 1993. 230p.

LU, H.; ZOU, W. X.; MENG, J. C., HU, J.; TAN, R. X. New bioactive metabolites produced by Colletotrichum sp, an endophytic fungus in Artemisia annua, Plant Science, Limerick, v. 151, n. 1, p. 67-73, 2000.

MARUCCI, R. S.; JERKE, G.; NAIDICH, A.; KNASS, P. Micoflora presente en yerba mate envasada comercializada en ciudad de Posadas provincia de Misiones, Argentina. In: CONGRESSO SULAMERICANO DA ERVA MATE, 2 , REUNIÃO TÉCNICA DA ERVA MATE, 3 , 2000, Porto Alegre, Anais... Porto Alegre: UFRGS/FEPAGRO, 2000, p.166-168.

MELO, I. S.; AZEVEDO, J. L. Controle Biológico. Jaguariúna: Embrapa Meio Ambiente, 1998. v.1.

MENEZES, M.; OLIVEIRA, S. M. A. Fungos Fitopatogênicos. Recife: Universitária, 1993. 227p.

PENNA, E. B. da S. Microrganismos endofíticos em erva-mate (Ilex paraguariensis St. Hil.) e variabilidade genética em Phyllosticta sp. por RAPD. 123f. Dissertação (Mestrado em Ciências Biológicas) - Universidade Federal do Paraná, Curitiba, 2000.

PENTEADO, S. R. C. Principais pragas da erva-mate e medidas alternativas para o seu controle. In: WINGE, H.; FERREIRA, A. G.; MARIATH, J. E. A. Erva-mate; biologia e cultura no Cone Sul. Porto Alegre: UFRGS, 1995. p.109-120.

PEREIRA, J. O.; AZEVEDO, J. L.; PETRINI, O. Endophytic fungi of Stylosanthes: a first report. Mycologia, New York, v. 85, n. 3, p. 362-364, 1993.

PETRINI, O. Taxonomy of endophitic fungi of aerial plant tissues. In: FOKKEMA, N.J.; HEUVEL, J. van DEN (Eds.) Microbiology of the phyllosphere. Cambridge: Cambridge University Press, 1986, p.175-187.

PETRINI, O. Fungal endophytic of tree leaves. In: ANDRENA, J.; HIRANO, S. S. (Eds.). Microbial ecology of leaves. Berlin: Springer-Verlag, 1991. p.179-197.

PIMENTEL, I. C. Fungos endofíticos do milho (Zea mays L.) e de soja (Glycine max (L.) Merril) e seu potencial biotecnológico no controle de pragas agrícolas. 153f. Tese (Doutorado) - Setor de Tecnologia, Universidade Federal do Paraná, Curitiba, 2001.

RODRIGUES, K. F.; SAMUELS, G. J. Letendraeopsis palmarum, a new genus and species of cleistothecial Loculoascomycetes. Mycologia, New York, v. 86, n. 2, p. 254-258, 1994.

SAATKAMP, K. E.; PIMENTEL, I. C.; GABARDO, J.; BORGES, L. R.; BEUX, M. R. Comparação entre meios de cultura para contagem de fungos no controle microbiológico da erva-mate. In: CONGRESSO SUL-AMERICANO DA ERVA MATE, 2., REUNIÃO TÉCNICA DA ERVA MATE, 3., 2000, Porto Alegre, Anais... Porto Alegre: UFRGS/FEPAGRO, 2000, p.186-188.

SMITH, H.; WINGFIELD, M. J.; PETRINI, O. Botryosphaeria dothidea endophytic in Eucalyptus grandis and Eucalyptus nitens in South Africa, Forest Ecology and Management, Amsterdam, v. 89, n. 1/3, p. 189-195, 1996.

STROBEL, G.; TORCZYNSKI, R.; BOLLON, A. Acremonium sp. - a leucinostatin A producing endophyte of European yew (Taxus baccata), Plant Science, Limerick, v. 128, n. 1, p. 97-108, 1997.

STROBEL, G. A.; FORD, E.; WORAPONG, J.; HARPER, J. K.; ARIF, A. M.; GRANT, D. M.; FUNG, P. C. W.; CHAU, R. M. W. Isopestacin, an isobenzofuranone from Pestalotiopsis microspora, possessing antifungal and antioxidant activities. Phytochemistry, Oxford, v. 60, n. 2, p. 179-183, 2002.

TAECHOWISAN, T.; PEBERDY, J. F.; LUMYONG, S. Isolation of endophytic actinomycets from selected plants and their antifungal activity. World Journal of Microbiology \& Biotechnology, Berlin, v. 19, n. 4, p. 381-385, 2003.

VIÉGAS, A. P. Dicionário de fitopatologia e micologia, São Paulo: Ceres, 1979. 882p. 